\title{
DISCUSSION
}

\section{On seismic landslide hazard assessment}

J. YANG (2007). Géotechnique 57, No. 8, 707-713

\section{A. D. W. Sparks, University of Cape Town}

Most analysts would accept the view by J. Yang that the static pore water pressure can be multiplied by the factor (1 $+k_{\mathrm{v}}$ ) during a dynamic seismic event. However, cohesionless loose saturated sands pose extra problems.

The writer's view relating to pore pressure behaviour during an earthquake can be summarised by the statement that 'during a seismic event, a saturated cohesionless sand which is looser than the critical void ratio, and is subjected to a shear stress, can compress in such a manner that the pore pressure can in theory increase (if drainage is retarded) to a maximum value equal to the static vertical total stress.'

Confirmation of the above statement can be found in an experiment performed by Heidari \& James, described by Pappin (1991). The diagrams plotted in fig. 7.24 in Pappin's work showed that, within three or four cycles in a centrifuge, the excess water pressures equalled the original vertical effective stress. In other words, the final water pressure (during this dynamic event) became equal to the vertical total stress. In the method of slices, the pore pressure force $U$ acting across the bottom of the slice can increase until it reaches a maximum value equal to the normal total force $W_{\mathrm{n}}$ during a seismic event in a saturated cohesionless loose soil (see Fig. 8). During this process, the effective force $P_{\mathrm{n}}$ that acts across the sliding surface, and the shear strength, both reduce to zero.

Let $k_{\mathrm{Sv}}$ be the downward vertical extra seismic acceleration for soil self-weight $W$, and $k_{\text {sh }}$ be the horizontal acceleration for the soil self-weight towards the down-slope. If a surface load $Q$ exists above the soil, it can be subjected to seismic accelerations $k_{\mathrm{qv}}$ and $k_{\mathrm{qh}}$. In other words, the vibration of the soil weight $W$ can be out of sync with the vibration of the surface load $Q$.

During an earthquake of short duration, it may be possible that $U$ will reach an intermediate value $U_{\text {quake }}$ between $U_{0}^{*}=U_{0}\left(1+k_{\mathrm{sv}}\right)$ and its maximum value $W_{\mathrm{nq}}$, where $W_{\mathrm{nq}}$ is the value of $W_{\mathrm{n}}$ after modification by terms such as $k_{\mathrm{sv}}$, and $U_{0}$ is the static (non-seismic) value of $U$.

Let us define a liquefaction ratio $L_{\mathrm{r}}$ as

$$
L_{\mathrm{r}}=\frac{U_{\text {quake }}-U_{0}^{*}}{U_{\max }-U_{0}^{*}}=\frac{U_{\text {quake }}-U_{0}^{*}}{W_{\mathrm{nq}}-U_{0}^{*}}
$$

The value of $L_{\mathrm{r}}$ is zero when the saturated sand does not

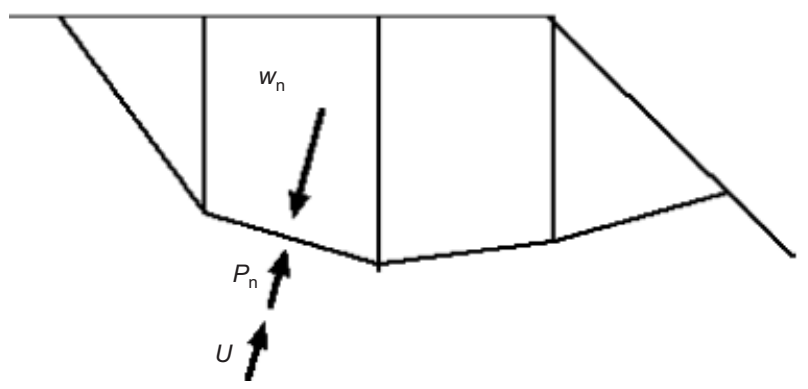

Fig. 8. During an earthquake in loose cohesionless soil the force $U$ can increase to value $W_{\mathrm{n}}$, while the force $P_{\mathrm{n}}$ reduces to zero have a tendency to change its volume (that is, when $\left.U_{\text {quake }}=U_{0}^{*}\right)$, and it is unity when the value of $P_{\mathrm{n}}$ becomes zero. In densely compacted saturated sands $L_{\mathrm{r}}$ may have a negative value. The analyst can choose the value of $L_{\mathrm{r}}$ to be used in computations.

For a particular slice, the writer prefers to use the equations

$$
\begin{aligned}
W_{\mathrm{nq}}= & {\left[W\left(1+k_{\mathrm{sv}}\right)+Q\left(1+k_{\mathrm{qv}}\right)\right] \cos \beta } \\
& -\left(W k_{\mathrm{sh}}+Q k_{\mathrm{qv}}\right) \sin \beta
\end{aligned}
$$

where $\beta$ is the angle of the slope of the slip surface under the slice, $W$ is the weight of the soil slice, and $Q$ is the surface load acting on this slice of soil; and

$$
U_{\text {quake }}=L_{\mathrm{r}} W_{\mathrm{nq}}+U_{0}^{*}\left(1-L_{\mathrm{r}}\right)
$$

where

$$
U_{0}^{*}=U_{0}\left(1+k_{\mathrm{sv}}\right)
$$

The factor of safety FS for the whole slide (using all slices) is equal to

$$
\mathrm{FS}=\frac{c^{\prime} \Sigma L+\tan \phi^{\prime}\left(\Sigma W_{\mathrm{nq}}-\Sigma U_{\text {quake }}\right)}{D}
$$

where

$$
\begin{aligned}
D= & \sum\left\{\left[W\left(1+k_{\mathrm{sv}}\right)+Q\left(1+k_{\mathrm{qv}}\right)\right] \sin \beta\right\} \\
& +\sum\left[\left(W k_{\mathrm{sh}}+Q k_{\mathrm{qv}}\right) \cos \beta\right]
\end{aligned}
$$

The above equations have been used to analyse the slope and building in Fig. 9, and the results have been plotted in Fig. 10. The equations yield straight lines for any fixed

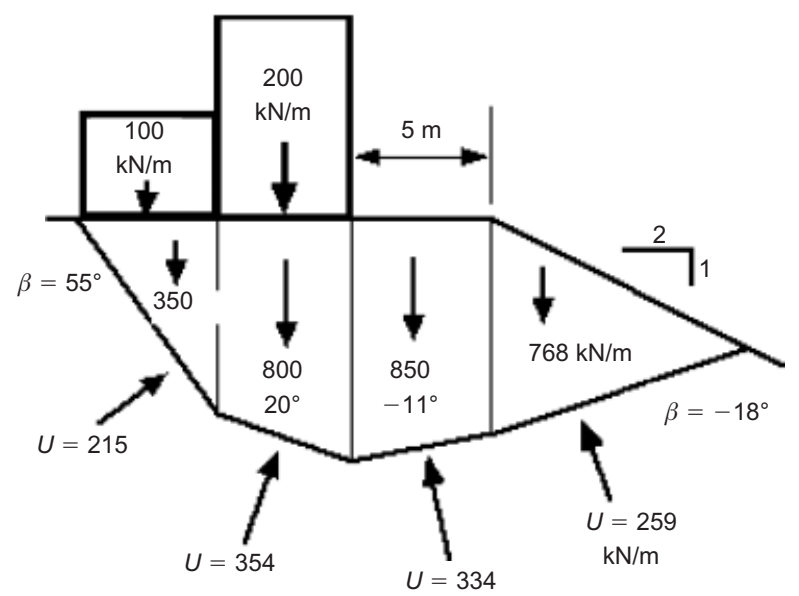

Fig. 9. Building on a slope: results for a seismic event are shown in Fig. 10 


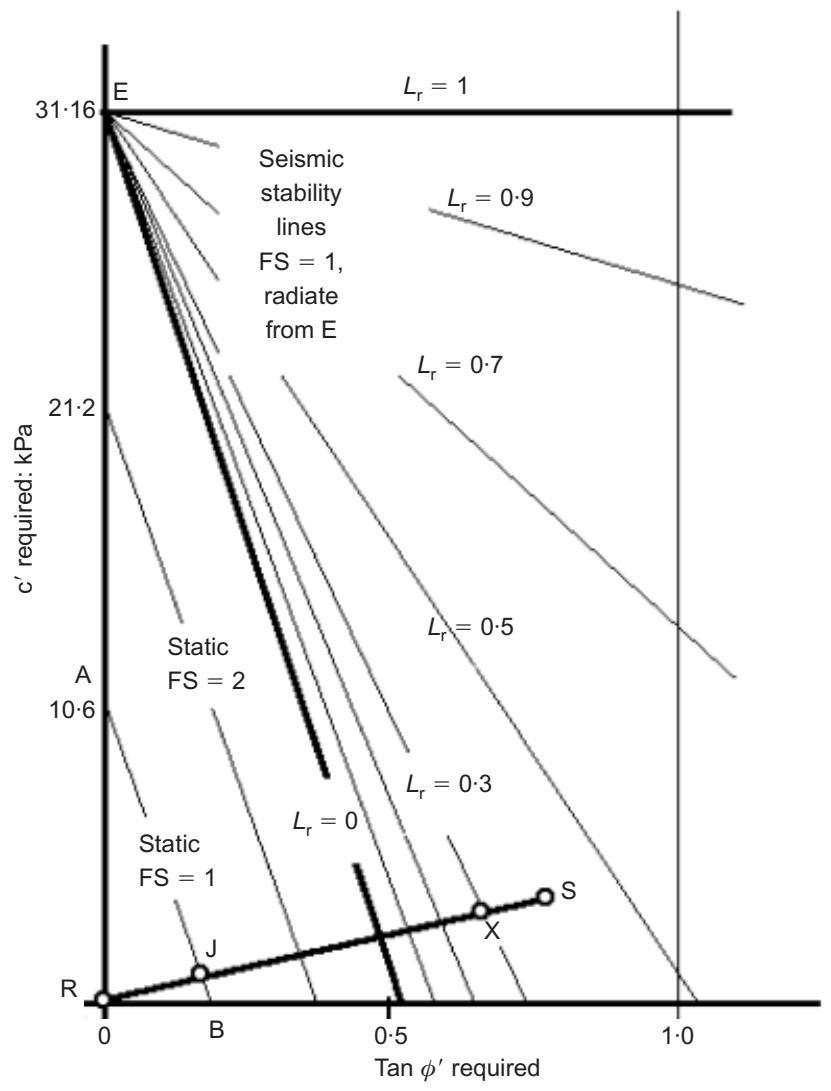

Fig. 10. Solid lines converging at point $\mathbf{E}$ are stability lines $(\mathrm{FS}=1)$ for seismic event using $k_{\mathrm{qv}}=k_{\mathrm{sv}}=0 \cdot 1$ and $k_{\mathrm{qh}}=$ $\boldsymbol{k}_{\mathrm{sh}}=\mathbf{0} \cdot \mathbf{2}$

factor of safety FS for this particular slip surface, as in Fig. 10. If the in situ soil strength is plotted as point $\mathrm{S}$ in Fig. 10 then the factor of safety FS for the static case is (distance RS)/(distance RJ).

If the value of $L_{\mathrm{r}}$ is $0 \cdot 3$ then the value of FS for this particular trial sliding surface is equal to (distance RS)/ (distance RX). Future research will show that the value of $L_{\mathrm{r}}$ will depend on the duration and intensity of the earthquake, on the relative density of the soil, and on the ratio of the original imposed shear stress to the original average effective stress. The value of $L_{\mathrm{r}}$ can also depend on the existence of impermeable layers (e.g. clay or calcrete layers), which can retard the dissipation of excess pore pressures in a loose cohesionless saturated material located under such impermeable layers. Clay layers overlying loosely packed saturated sand (or even a loose saturated gravel) can cause the loose material to lose its ability to carry a surface load during an earthquake (see Fig. 11).

If $L_{\mathrm{r}}$ is equal to zero, and there are no surface loads $Q$, then the above equations provide the same values for the factor of safety as those produced by Yang in his Fig. 2(b).

\section{Author's reply}

The author thanks Professor Sparks for his interest in the paper. He raises in the written discussion an issue concerning excess pore water pressure and soil liquefaction during earthquakes. This effect has long been recognised, but it is commonly neglected in models for spatially distributed landslide hazard assessment. This is due in part, as mentioned in the original paper (page 708), to the great difficulty and uncertainty involved in the evaluation of seismic pore water pressure, and for the purpose of retaining simplicity.

It is indeed straightforward, as shown by the discusser, to express the excess pore water pressure as a fraction of the effective normal stress on the slip plane in the framework of

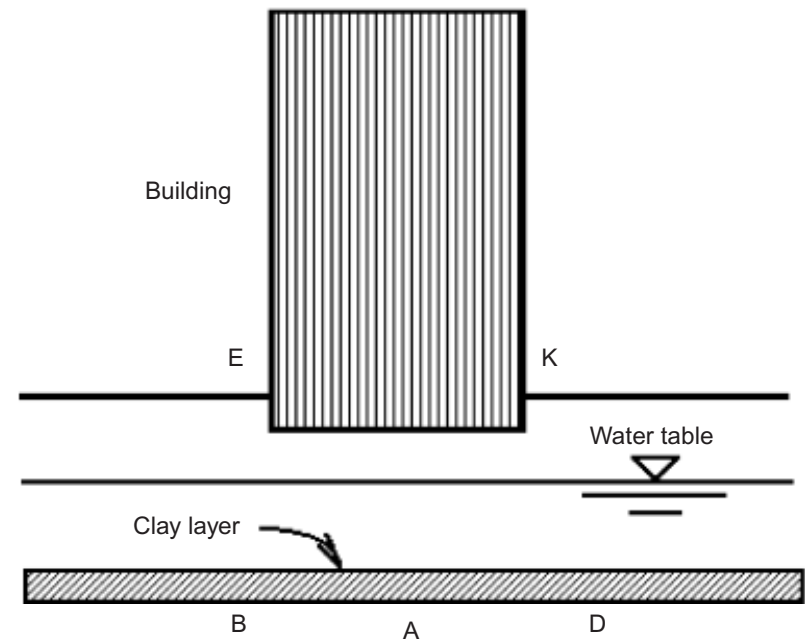

Fig. 11. During a seismic event the pore pressure $U$ at A can increase to the value of the total stress at $A$. The building will sink and tilt because of the soup-like material at A. Also, the excess pore pressure at $A$ dissipates to $B$ and $D$. Water breaks out as a quicksand from $B$ to $E$, and from $D$ to $K$

the analysis. However, it remains a difficult task to develop an appropriate model for estimating seismic pore water pressures for routine engineering practice. This is because the rise of pore water pressure in a sloping ground during earthquakes is influenced by many factors that are not yet well understood. In this respect, the author would like to offer several observations, as follows.

(a) The soil in a sloping ground is always subjected to an initial driving shear stress prior to seismic loading (element A in Fig. 12), as compared with level ground

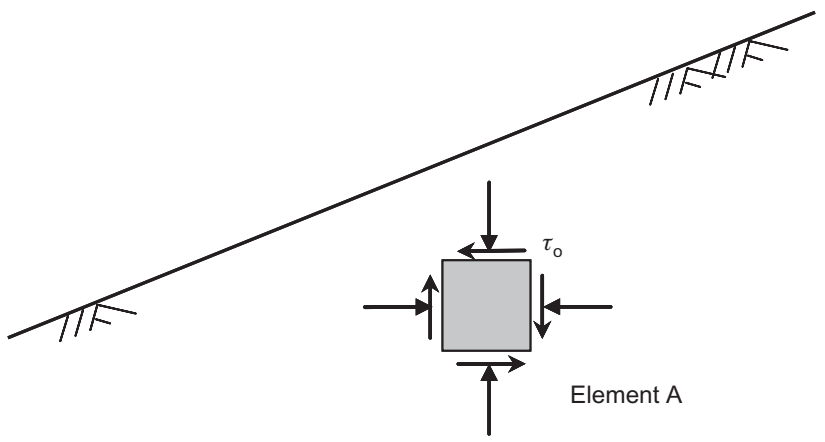

(a)
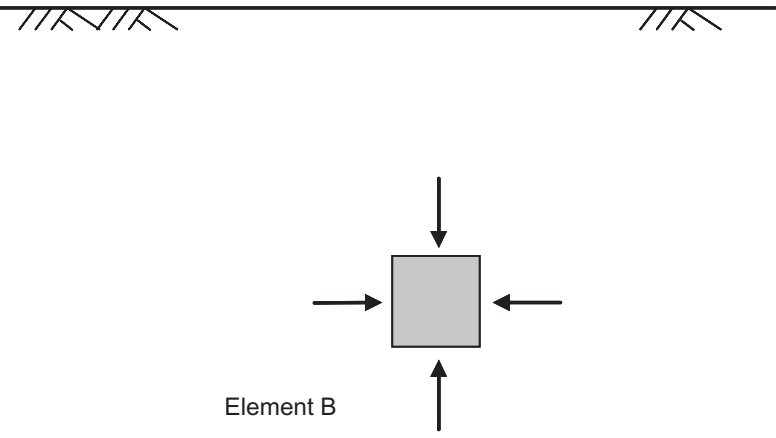

(b)

Fig. 12. In situ stress conditions in (a) sloping ground and (b) level ground 

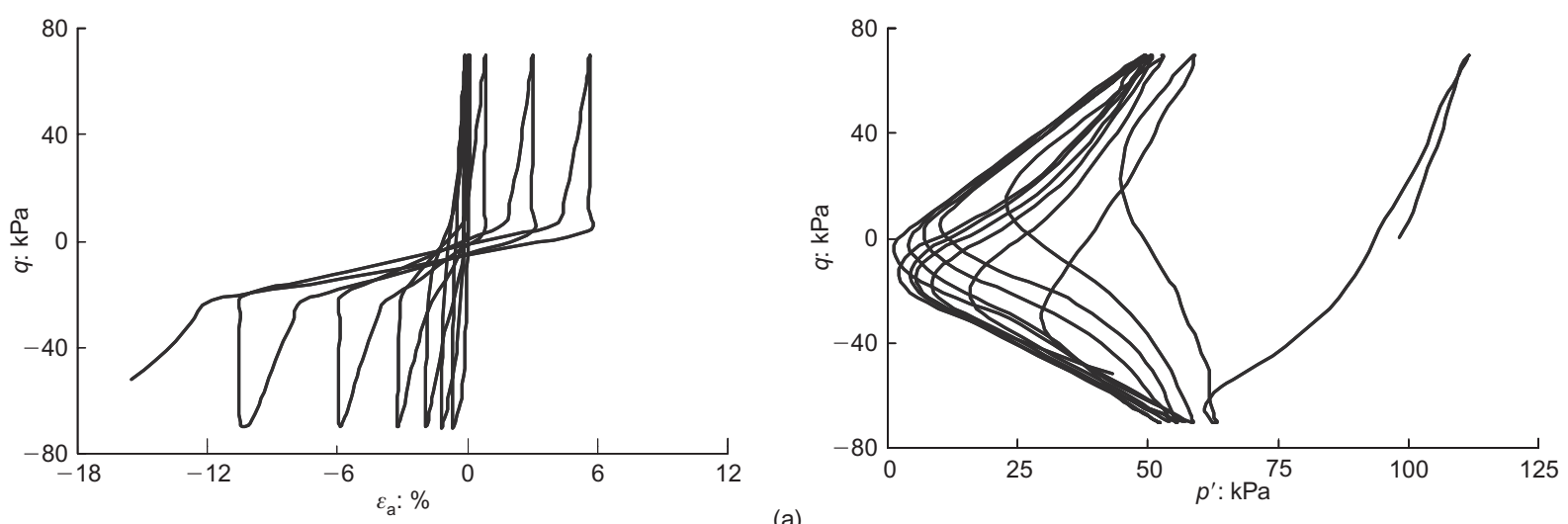

(a)
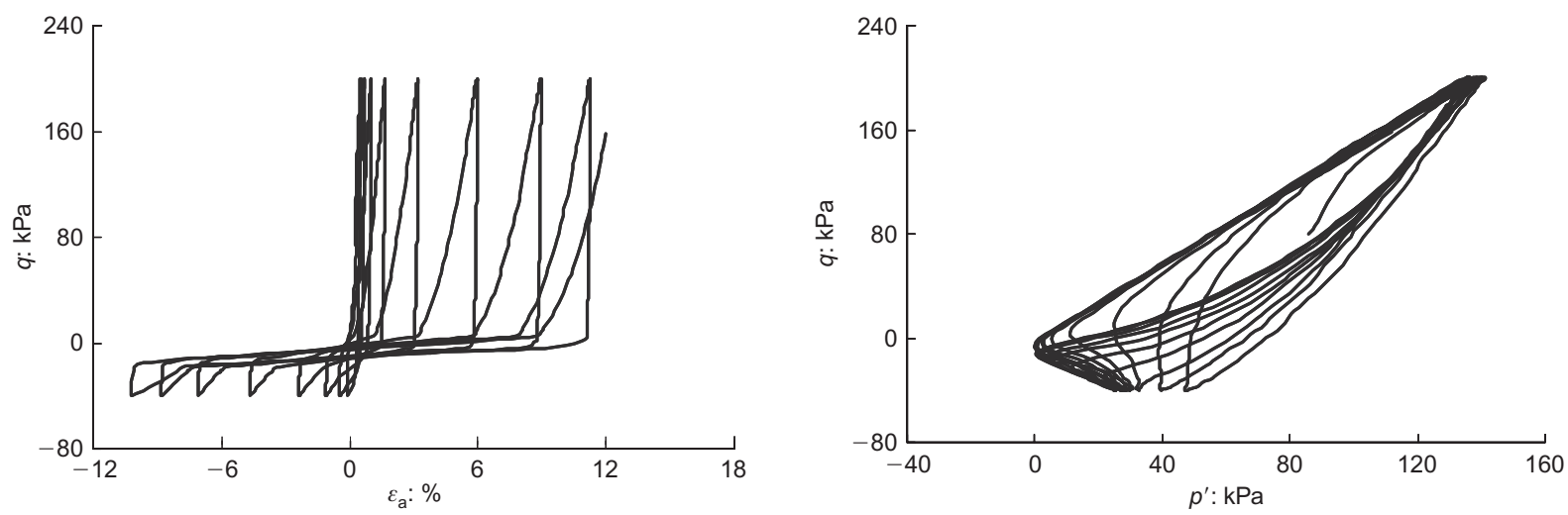

(b)

Fig. 13. Cyclic triaxial behaviour of sand: (a) without initial shear stress; (b) with initial shear stress

conditions in the free field, where no initial static shear stress acts on the horizontal plane of the soil (element $\mathrm{B}$ in Fig. 12). The initial static shear stress can exert significant influence on the development of excess pore water pressure and shear deformation (e.g. Seed, 1983). An example of this influence is shown in Fig. 13 using the author's experimental data on the cyclic triaxial behaviour of two saturated sand specimens. The two specimens were consolidated to the same relative density $(\sim 50 \%)$ and the same normal stress $(\sim 100 \mathrm{kPa})$ on the plane of interest: one specimen was subjected to an initial static shear stress on the plane of interest, and the other was not. It should be noted that the effect of initial shear stress on the resistance of sand to liquefaction can be beneficial or detrimental, depending on several factors (e.g. the relative density of sand, the magnitude of static shear stress relative to the normal stress, and the stress reversal). The problem as to properly quantifying the effect for routine use still remains to be solved.

(b) The effect of vertical seismic loading on pore water pressure build-up and soil liquefaction is another issue to be investigated further. The author made an attempt to address this issue for level ground conditions (Yang, 2004). He showed that this effect depends on the saturation condition of soil: when the soil is fully saturated, the inclusion of vertical seismic loading has a minor influence on pore water pressure build-up, but when the soil is not fully saturated, the influence may become substantial. In the meantime, much greater amplification of vertical ground motion can occur under partially saturated conditions than under fully saturated conditions. Even without the involvement of vertical seismic loading, the resistance of soil to liquefaction can also be significantly affected by the degree of saturation (see Yang et al., 2004, and the references therein): a partially saturated sand specimen shows higher resistance to liquefaction than a fully saturated specimen. Apparently, the coupling of these effects, along with the sloping ground conditions, may bring about great difficulty and uncertainty in the evaluation of seismic pore water pressures in slopes.

(c) One major advantage of the pseudo-static approach combined with the Newmark sliding block theory lies in that it provides a useful way of screening for seismic landslides hazard and other stability problems in geotechnical applications. On the other hand, the approach suffers several well-known limitations related to simplifications. When there is a need to go beyond this simplified approach, comprehensive numerical procedures such as fully coupled, elastic-plastic finite element analyses in the time domain should be sought. One of the recent advances worth mentioning is that the strong material non-linearity and geometry nonlinearity as well as the pore water pressure response involved in the large deformation of liquefying soil masses during earthquakes can now be successfully allowed for (Di et al., 2007).

\section{REFERENCES}

Di, Y., Yang, J. \& Sato, T. (2007). An operator-split ALE model for large deformation analysis of geomaterials. Int. J. Numer. Anal. Methods Geomech., 31, 1375-1399.

Pappin, J. W. (1991). Design of foundations and soil structures for 
seismic loading. In Cyclic loading of soils (eds M. P. O'Reilly and S. F. Brown), pp. 334-335. Glasgow: Blackie.

Seed, H. B. (1983). Earthquake resistant design of earth dams. Proceedings of the symposium on seismic design of embankments and caverns, ASCE, pp. 41-64.
Yang, J. (2004). Reappraisal of vertical motion effects on soil liquefaction. Géotechnique 54, No. 10, 671-676.

Yang, J., Savidis, S. \& Roemer, M. (2004). Evaluating liquefaction strength of partially saturated sand. J. Geotech. Geoenviron. Engng, ASCE 130, No. 9, 975-979. 